\title{
Diversity and health strategies for newly resettled refugees
}

\author{
Linda Vikdahl, Göran Ståhle, David Gunnarsson and Fredrik Saboonchi
}

\begin{abstract}
Purpose - In general, newly resettled refugees have poorer physical and mental health than native-born Swedes. This indicates that the society must make special efforts to enable refugees to attain health that is on a par with the rest of the population. The challenges rest primarily with employees in the public sector. But what resources do professionals need to meet the refugees' health needs? This paper is about the need to develop strategies for professionals working with diversity and health, with a focus on the establishment of newly resettled refugees in Sweden. Thus, the purpose of this paper is to identify the needs and obstacles in working with diversity and health for the newly resettled.
\end{abstract}

Design/methodology/approach - The paper is based on focus group interviews with 40 professionals working in three large municipalities and one County Administrative Board, all of whom work with challenges related to migration and health on a daily basis.

Findings - The needs expressed by the interviewees are primarily about developing and improving communications. Three important areas of communication were expressed: how information can be transferred from sender to receiver, institutionalization and interactions at different levels.

Originality/value - This paper identifies important needs and obstacles when working with diversity and health in Sweden, with a focus on the establishment of newly resettled refugees. It is an important contribution because refugees in general have poorer physical and mental health than native-born Swedes and strategies to improve their health, therefore, need to be further developed.

Keywords Health, Strategy development, Professionals, Newly resettled refugees

Paper type Research paper

\section{Background}

It is well known that health is influenced by differences in people's living conditions. For example, poor nutrition and poor medical care adversely affect human health; most importantly, health inequalities are clearly linked to the social gradient (Marmot, 2005). Despite a prevailing focus on pre-migratory traumatic events as primary causes of ill health amongst forced migrants (Sigvardsdotter et al., 2016), the health of refugee populations can be seen as a case in point regarding the impact of social conditions on health (Miller and Rasmussen, 2017). In general, refugees display poorer physical (Jervelund et al., 2017) and mental health (Bogic et al., 2015) than native-born inhabitants. Refugees resettled in Western countries are ten times more likely to have post-traumatic stress disorders than age-matched general populations in those countries (Fazel et al., 2005). Migration itself is a very complex phenomenon and the individual refugee goes through a series of adjustment stages and is exposed to a number of stressors associated with the preparation process, as well as post-migration adjustment (Bhugra, 2004; Bogic et al., 2015). Newly resettled refugees can experience social exclusion because of not being able to speak the host society's language, not having a job or by experiencing discrimination and a lack of access to important social resources, which in turn imply an increased risk of mental ill-health and distress. Although a heterogeneous group, refugees' health, thus, is affected by and affects the process of social establishment and integration in the host
Linda Vikdahl, Göran Ståhle and David Gunnarsson all are based at Sodertorns Hogskola, Huddinge, Sweden. Fredrik Saboonchi is based at the Department of Health Sciences, The Swedish Red Cross University, Huddinge, Sweden and Department of Neuroscience, Karolinska Institutet, Stockholm, Sweden.

Received 23 August 2019 Revised 4 April 2020 Accepted 8 May 2020

(C) Linda Vikdahl, Göran Ståhle, David Gunnarsson and Fredrik Saboonchi.Published by Emerald Publishing Limited. This article is published under the Creative Commons Attribution (CC BY 4.0) licence. Anyone may reproduce, distribute, translate and create derivative works of this article (for both commercial and non-commercial purposes), subject to full attribution to the original publication and authors. The full terms of this licence may be seen at http://creativecommons. org/licences/by/4.0/legalcode

The authors are grateful to those at Red Cross University College, Flemingsberg Science, Huddinge and Botkryrka municipalities, and the Stockholm County Administrative Board who contributed to the study. Thanks specially to Björn Varnestig \& Pernilla Boström, and all the participants in the interviews.

Funding: The study was made possible by funding from Red Cross University College, Flemingsberg Science, Huddinge and Botkyrka municipalities, Stockholm County Administrative Board and Swedish Research Council for Health, Working Life and Welfare (Grant 2016-07194) 
country. In the same line, the World Health Organization (WHO) states that refugees' health related to migration is a key public health challenge for nations and societies (WHO, 2008).

This article concerns strategy development for professionals working with diversity and health and focuses on the establishment of newly resettled refugees in Sweden. "Newly resettled refugee" is used for a foreign citizen who has come to Sweden in recent years and who has been granted residence permits and protection on the basis of refugee-like reasons, or alternatively through family reunification with such a person, and who has been received in a municipality (Tinghög et al., 2016). The article is based on interviews with 40 professionals from three large municipalities and county organizations in Botkyrka Municipality, Huddinge Municipality and Stockholm County Administrative Board (Vikdahl et al., 2018), all of which have a responsibility for ensuring the good health of newly resettled refugees in the area. Some of the questions put to the interviewees were: What do you need to improve your work? Do you have the necessary knowledge to perform your work satisfactorily? What problems can you identify in your organization's work with diversity and health with a focus on the establishment of refugees?

The interviewed professionals are what Michael Lipsky (2010) labelled as "street-level bureaucrats". They are the implementers of policies and the frontline service providers who might also be viewed as the makers of policies when they resolve ambiguities and inconsistencies in the orders and statutes (Brodkin, 2008). Whereas the management tends to be directed towards policy goals, accountability and evaluation, the frontline providers are inclined towards a client perspective and autonomy, to meet the demands of a current situation (Hill and Lynn, 2016).

As mentioned earlier, this article is based on the concept of social determinants of health (Navarro, 2009) that are relevant to the professionals' activities. According to this model, health is understood as an interaction between the individual and the society, where the society's welfare institutions provide resources that enable individuals to live healthy lives, experience well-being and participate in the society. Thus, health is not just a matter of health care and medical care but is something that the various community actors included in the survey need to consider in their daily work. In a broader sense, this is in line with a definition of health as not simply the absence of illness but as a part of social sustainability. Such a definition of health is also in line with various action programmes, such as WHO's Ottawa Manifesto and the UN's Agenda 2030. This approach takes different layers of determinants into account. In addition to the individual, biological determinants and health, structural factors (e.g. the environment, laws, policies and regulations), social and societal factors (such as housing and working conditions) and behavioural and living factors (like diet and exercise) (Dahlgren and Whitehead, 1991) are also important. Furthermore, the concept of well-being lays at the core of WHO's seminal definition of health (Constitution of the World Health Organization, 1946). Thus, well-being is indistinctly related to health. However, as there are cultural and social differences in how a specific health condition is rendered, the two concepts are not necessarily interchangeable. The concept of well-being can be quantified in terms of quality of life and also studied through qualitative interviews on satisfaction of life, happiness and inner peace (Dooris et al., 2018). Consequently, a broader approach to health and well-being involves a multitude of stakeholders and is not limited in scope to health-care and biomedical professionals. The non-biological determinants of health are considered as modifiable and possible to influence through political goals and guidelines and actions. Thus, the focus of such an approach is on resources, support and opportunities for resilience, not solely on medicine.

Additionally, street-level bureaucrats (Lipsky, 1980) have an important role in this regard, as their decision-making and management strategies directly affect the social and living conditions of the citizens. Given that policies and regulations are channelled into the refugees' everyday lives through the discretion of these professionals, street-level bureaucrats constitute important stakeholders in the post-resettlement health of refugees. 


\section{Method}

The interviews took place at Södertörn University. They were conducted in focus groups, because the focus group method has proved to be very useful for exploring how people think about a topic and for gaining knowledge about why they think as they do (Morgan and Krueger, 1993; Krueger and Casey, 2008). The knowledge generated during the focus group interviews reflects the interviewees' common experiences of the subject and focuses on the variation in the collective understanding that emerged from these discussions (Kitzinger, 1994). There were three to nine participants in each focus group.

The interviews lasted for about an hour. They were open-ended and sometimes took the form of a conversation. This approach was chosen because the aim was to identify new and partly unexpected needs for strategy development for working with diversity and health, with a focus on the establishment of refugees in Sweden. In the interviews, the interviewees talked about their experiences of the subject, and the research group asked new questions in connection with these experiences.

All the interviewees were interviewed in their professional capacity. Everyone had assignments in their daily work that involved challenges related to migration and health. For the empirical work to become as rich as possible, we looked for interviewees with different work functions and positions. This means that the material contains statements from people working at different levels and having different assignments and directions as actors. All the interviewees were involved in one way or another with the establishment of refugees in the society.

Before the focus group interviews, all the interviewees were invited to an information session about the study. The various information meetings were held on different days and at different times, so that the participants could choose which suited them best. The purpose of the information sessions was partly to provide details about the study and partly to prepare the interviewees for the upcoming focus group interviews. The participants were also informed of their rights according to the Swedish Ethical Review Act. According to this act, research can only be carried out if people consent to participate (SFS, 2003:430) and have received information about the methods, the risks, who the research leader is, that participation is voluntary and that they have the right to withdraw their participation at any time (Lövgren et al., 2012).

The focus group interviews were recorded and transcribed. The transcriptions were analysed using sentence categorization (Kvale, 1997), which basically means that the interviews were coded into the different categories that emerged after repeated readings of the empirical material. The concept of 'strategy development' functioned as a sensitizing concept (Blumer, 1969), which means that the research group reflected on what 'strategy development' was about in the material and created categories based on these reflections.

\section{Previous research}

International research has also confirmed that improving the health of newly resettled refugees involves a lot of work for municipalities, health-care institutions and other social actors. Refugees experience several barriers to accessing health-care systems. For example, communications between health-care service providers and patients are of key importance for building trust in health-care institutions, where insufficient health literacy and language issues may constitute significant barriers (Lazar et al., 2013). Additional refugeerelated factors, such as socio-economic positions in the host society, gender roles, lack of adequate information, difficulties in navigating the health-care services and cultural beliefs and practices with regard to health and illness may potentially hamper access to health care (Conviser, 2007; Evans, 2011; Lazar et al., 2013; Cheng et al., 2015; Gerber et al., 2017; Pejic et al., 2017; Worabo, 2017). Engaging the refugee communities in the development of health-care policies and their delivery, as well as participatory health-care 
research, is suggested as a way of removing the barriers to care (Lindgren and Lipson, 2004; Lazar et al., 2013; Cheng et al., 2015; Riggs et al., 2015; Pejic et al., 2017).

It is also shown that refugees and asylum seekers trust in their host countries' health-care systems is of great importance. If they do not trust the system, then they will be less motivated to seek help on health issues. Research shows that communication and community engagement are vital aspects of developing trust in the health services amongst refugee care-seekers (Lazar et al., 2013). One study even indicates that system changes could be a key to changing health-seeking behaviour amongst poor and disadvantaged social groups (Conviser, 2007). It is also recognized that people from different religious and cultural backgrounds differ with respect to health-seeking behaviour and attributions of sickness and disease aetiologies. This underscores the importance of cultural awareness and sensitivity for people who meet refugees in their occupation and reflexivity with regard to tacit positions and assumptions in one's own organization (Vaughn, 2019).

An interesting and relevant analysis in this context is a Swedish environment analysis based on research that was carried out in Region Skåne (southern Sweden) in 2017. One purpose of the analysis was to identify focus areas for working with equal health for refugees. This resulted in a number of suggested initiatives some of which are at a structural level and concerned changes related to organizational processes such as business planning and budgeting. Other efforts concern collaboration with actors involved in migration and health. Several of the migration and health initiatives require actors to cross administrative and organizational boundaries to collaborate effectively.

\section{Theoretical framework}

Regarding the above findings of previous research on newly resettled refugees, it comes as no surprise that communication between and within different levels of organizations is crucial. Therefore, the analysis is based on a theoretical model from the research area of intercultural communication (Jensen and Halkier, 2011; Dahl et al., 2007). This perspective focuses on the dynamics and dimensions of the strategies that individuals use in relation to diversity and health in their respective contexts. The starting point for the analysis is how the actors describe and experience their professional roles in relation to communication in and across organizational borders and cultures. The main issue is how communication could be as constructive as possible, without misunderstandings and breakdowns. A qualitative method was used to analyse the individuals' interview responses because this facilitates a thorough understanding of the processes and contexts in which people experience and create social and cultural borders.

According to the intercultural communication model, all human interaction involves strategies for handling differences and similarities. Dahl (2014) calls this a "dynamic" perspective on culture, where culture is construed as something that people create, that is, where the focus is on various processes of cultural construction. This does not always follow lingual, national or ethnic patterns, but all human interactions involve the potentialities of estrangement or solidarity. The people in this study were active in workplaces with complex organizational structures where both colleagues and clients had multiple backgrounds. From the perspective of intercultural communication, we could discern the interplay of borders and crossings and how differences and similarities, estrangement and solidarity were interpreted.

\section{Results}

In the study, we identified three main models of communication. The first focuses on how information is transferred from sender to receiver. One of the main issues here is how information can be as effective and free from disturbance as possible. In this perspective, cultures are potential obstacles and the goal is to reduce these barriers. The keyword here 
is knowledge, because the greater the knowledge of the participants, the smoother the transfer of information is likely to be. The second model includes networking and cooperative aspects, where communication is seen as an interplay of more or less engaged participants. Here, open interaction is the keyword, with human exchange, dialogue and networking being highlighted as important strategies. The third model is institutionalization. Structure and predictability are seen as key elements that guarantee an undisturbed flow of information.

\section{Obstacles to communication}

The interviewees identified key obstacles when working with health-related issues for newly resettled refugees. According to the above-mentioned theoretical model, these can be described as obstacles to communication in terms of different organizational cultures and social categorizations. Several reflected on what they perceived as the saliency of gender equity in discussions about equality in the workplace and the forming of interventions. They were aware of a gender imbalance that needed to be considered when planning their work and implementing the interventions. However, the interviewees problematized that the same awareness was not evident when it came to other categorizations, such as ethnicity, age or disability. This is in concordance with arguments about the decentring of gender and sex as classifications and the potential gains in health-related practices (Hankivsky, 2012). These arguments were repeated by many of the interviewees, who saw a need to make other categorizations as equally relevant as gender:

So, what I would like is that in five years it would be somehow natural not to just think 'aha, refugees and ethnicity' and forget about all the other things that actually affect their possibilities to participate in society, or the labour market, or whatever. I'm not sure what we would need to do to get there, but some sort of [...] improved competence so that we can also talk about these matters in a natural way with other actors and colleagues etc. (L180315)

The problem here seems to be one of communication. As addressed in previous research, communication is a vital part of developing trust for the health services amongst refugees seeking care (Lazar et al., 2013). In this context, system changes could be a key to changing the health-seeking behaviour of the disadvantaged social groups (Conviser, 2007). Communication is dependent on categorization, because this sets the limits for our understanding of what can be done and by whom:

\footnotetext{
When it comes to men and women, for example, then we have a [...] You start from the assumption that, okay, in this workplace we are all formally equal. We're all equal before the law, everyone can vote and so on. But despite that things can happen that make it necessary to follow up on how men and women feel, whether they are happy in their workplace and even what they think about the temperature in the room. We want to know if they think differently. But at that level there's no discussion about skin colour and no follow-up in the same way. And then [...] That's what I mean as well. That's what makes it hard to work for equality, equal health, equal whatever you like, because the point of departure is that we can't have any problems around those things. (L180309)
}

\section{The knowledge aspects of communication}

The focus groups identified how obstacles in communication could be solved by facilitating and improving the transfer of information and knowledge across organizations and sectors. Five areas of requested information transfer were identified: a need for research (analyses and statistics), a need for a question bank/expert advice/guidance, knowledge about religion and culture, a need for a website with courses offering further education and knowledge about the implementation of new laws and policy decisions.

The interviewees agreed that research on diversity and health, in a broad sense, was lacking. One recurring quest was quality indicators in relation to different aspects of 
diversity. They asked for statistics that could be used to better estimate efforts for citizens and newly resettled refugees. Altogether, more detailed analyses before initiatives were carried out were requested to do a qualitatively good job. Qualitative research was also requested. Although some of the interviewees did not work directly with citizens and newly resettled refugees in their professional practice, their decisions did affect the newly resettled refugees' life situations, albeit at a strategic level. Therefore, they wanted to hear the stories of citizens and the newly resettled to make sure that they made the correct decisions. One interviewee said:

I think that the majority of us have been in contact with healthcare in some way and sometimes need a bit more [...] Statistics are very good, but knowledge can also be stories like "that was what happened when I was in contact with the dentist" or "dental care for children, this is what we experienced [...]". So I think that these kinds of stories are important. (L180315)

It was difficult for the interviewees to find the necessary information to respond to the needs of citizens and newly resettled refugees in appropriate ways. The lack of a clear source of information sometimes prevented the interviewees from carrying out their work, as they had to spend a lot of time searching for and compiling the information needed for a particular case. Several saw having a question bank/expert advice/guidance as a solution to this problem.

There were also clear requests for increased knowledge about religion and culture. The knowledge asked for was practical in nature, such as how to best work with people from different cultures and how awareness of people's different religious and cultural backgrounds could be more obviously included in their daily work. The interviewees tended to use a secular approach. This sometimes clashed with citizens' and new resettled refugees' religious beliefs, which then made it difficult for them to understand each other. They also wanted to know more about conflicts between different religious and cultural groups.

There was also an expressed need for increased knowledge about their own organizations. Amongst other things, the interviewees wanted help and guidance when it came to implementing new laws and policy decisions. They saw the need for issues relating to diversity and health and the establishment of refugees to be included in steering documents and policy decisions, as well as increased knowledge about their organization as a whole. One of the interviewees said:

It's very frustrating to go on courses and then have to communicate to my managers what l've learned and they don't understand. I've been on courses and learned new things about how we can improve our work. But there's no understanding at the next level. [...] So I think this is an

important aspect. They should go on courses and carry out their work, like us. (K180326)

\section{The networking and cooperative aspects of communication}

Although the participants identified the knowledge aspects that could improve communication, they agreed that the prime solutions concerned the networking and cooperative aspects of communication and that this should be seen in the light of the existence of a multitude of actors providing courses in intercultural competence. Knowledge about these issues was abundant, but the problem was how to organize and cooperate using the already existing knowledge.

When it came to multifaceted problems, it was not a lack of knowledge amongst the employees that created the problems, but rather the compartmentalization of tasks between different organizations. The focus groups highlighted how single axis organizations found multifaceted problems difficult to address. The undertakings of municipalities and authorities are often divided into different sections, each having their own areas of expertise and responsibility. One of the participants described some of the problems a refugee family 
might experience because of various agencies and authorities being geared towards their differing responsibilities, which meant that refugees, and especially those with disabilities, could easily slip through the safety net.

I have a case with a disabled mother who has fallen through the cracks. There's a real lack of cooperation in this case. She's been living in Sweden for ten years but has not been given the assistance that she and her family need. There has been a lot of suffering, both for her and for her children, criminality, suicide attempts and a lot of other things. I think that if there had been better cooperation earlier in this case some of the more serious problems could have been avoided [...] I think that there's a need to cooperate more around certain groups in society, such as those who are the most marginalized and have no social safety nets, the intellectually challenged and the disabled. My take is that this is all about health. (K180326)

Similarly, one of the focus groups (K180326) noted that if several organizations were involved in a case, then there was a tendency for nobody to take responsibility but to instead refer clients to other instances. The focus group argued that this could be counteracted by networking and by the actors in a case meeting up and making joint decisions.

Cooperation across organizational borders already existed. Many of the participants expressed that finding cooperative solutions around specific cases was a part of their daily work. Despite this, they also expressed a need for better ways of linking together across organizational borders and between people in different positions:

So, there is a need for someone in the middle who could link up everybody's different worlds, or words to that effect. Instead of cementing together we throw custard pies. That's the link that I think is missing. Understanding each other's perspectives. (K180327)

\section{The institutional aspects of communication}

Many of the participants took this reasoning a step further and argued that networking and interactions needed to be safeguarded and better established and that the channels and interfaces of communication needed to be further promoted. Today, the cooperation between different actors is often based on personal relations and the networks that different people build as a part of their everyday work. Therefore, the communication is dependent on these particular people and is based on commitment, rather than formalized functions:

It is so person-centred. We are quite free in our work to cooperate with others. Now we cooperate with Stockholm City Mission and there's a driving spirit there that really wants to work with us. It's about will. There's nothing written down. (K180326)

The fact that the contacts between different actors were based on personal relationships and not on institutionalized roles was regarded as problematic. For example, a problem could arise when someone left, and another person was employed. The accumulated relations could easily then be lost, given that they are based on personal commitment:

It's too person-centred. If I leave, the person who takes over may not have the same contacts as I have. That would make things very difficult. So, it's clear that a collaborative structure, or whatever you want to call it, is really needed. (K180327)

Another interviewee said:

It is so bound up with relations. You have people who you know, that you can call on and get input and support from, as professionals. I would really like it to be more dependent on functions, not so much on people. I think that the collaborative relations that we've succeeded in creating in our professional networks is very person-dependent. I think that's a flaw. (K180326)

The institutional aspects of communication were also seen to be in need of development at a national level, not only amongst local actors. Some of the interviewees said that there was 
confusion because different County Administrative Boards had their own practices for the same issues:

Every County Administrative Board is a government body, which adds to the confusion. Sometimes it would be good if all the County Administrative Boards worked in the same way. We get the same official directives, "this is what you have to do", but how they are carried out differs. We should communicate more across organizational borders. We do that in some matters, but in others we have to manage everything ourselves [...]. We could definitely be much better. But I don't know whether it would make things better. It might be the other way around. But it's an important aspect. (L180309)

Another interviewee from the County Administrative Board meant that if the work on diversity and health was to have any impact, then it had to be more rooted at the national level:

We get so many political directives, but we only work at the local and regional levels. The national perspective is missing [...] And it's not only in this area, but generally. You could say that they don't do their homework at the national level, which means that another directive comes, and another, and nothing really happens. (L180309)

The participants also expressed a need to develop the institutional aspects of communication between the official authorities and the civil society:

More cooperation with different actors! We work a lot with the church and we work with Stockholm City Mission. But we are still the municipality. We even get clients with problems that we don't have the skills for. Other actors, like Stockholm City Mission, are very good at working with integration and newly resettled refugees, so we send our clients to them instead because it's better that they work with them. But the municipality should really be able to take care of them. But that's not the case today. So we have to be flexible and cooperate, regardless of which is the responsible authority. (L180326)

One interviewee explained that the civil society sometimes had more advantages in the work with diversity and health than the municipalities, because it was able to reach out to people in different ways:

The civil society reaches out where the municipalities cannot. And they discover things much earlier, and so on [...] We as official actors should be better at recognizing them, highlighting them and taking them seriously and making it possible for them to continue doing what they are good at. (L180315)

Cooperation with the civil society was not only seen as necessary for reaching out but was also recognized as essential for helping refugees to participate socially in the society:

One thing that we talk a lot about, and that we see as a development area, is to work much more at the local level. To make it more natural to send people out and inform them about what there is. We are only there temporarily. It's about helping people to find others [...] I mean, if people are to be included in society they need more than relations with the social services. If you are a newcomer in this society, and you don't have the necessary information or take part in everything that exists [...] that's a development area I think. (L180326)

Another expressed need was to develop communications between different positions in the same organization. Several participants wanted the management to be better informed about issues like diversity and health:

I also think that it's a leadership matter and if there were more communications with and between the management and different managers at different levels it would have more of an impact. Information is important, but you also have to start working more on it yourself and learn how to do it. (L180315)

In sum, the problems presented by the focus groups concerned obstacles in intercultural communications. They identified several aspects of cultural and social categorizations that 
hindered communication. They also identified three different aspects of communication that characterized their everyday work with newly resettled refugees' knowledge, social and institutional aspects. There was an agreement that the social and institutional aspects were the most important.

\section{Conclusion}

It is easy to imagine that needs for developing work with diversity and health in Sweden, with a focus on newly resettled refugees, are about increased budgets, more staff or more resources. Whilst the availability of resources is certainly decisive to enabling and facilitating such work, there are also other profound and somehow neglected needs that are experienced by those professionals who work with newly resettled refugee populations. The needs expressed by the interviewees in this study primarily concerned developing and improving communications across and within the organizational structures that constitute their work platforms.

Three areas of communication were expressed as particularly important to develop.

The first is how communication obstacles could be overcome by facilitating and improving the access to, and transfer of, information and knowledge within and across organizations and sectors. The second pertains to the need for inter-organizational networking, cooperation and collaboration. This reflects a broad recognition that the health of diverse populations in general, and newly resettled refugees in particular, involves a multitude of stakeholders and organizational entities that need to be engaged in exchange, dialogue and communication. Institutionalization of such collaborative and cooperative exchange and communication constitutes the third area of needs. The interviewees considered structure and predictability to be necessary to guarantee an undisturbed flow of information. Establishing an efficient and well-functioning communication process across stakeholders and organizations is such an essential and extensive task that it should not rely solely on individual initiatives. Instead, it requires a high degree of formalization and institutionalization.

Lipsky (1980) suggests that analysing and understanding actions and routines, as well as perception and attitudes, of street-level bureaucrats is necessary for illuminating the real impact of policies and regulations on end users' living conditions. Whereas previous research has pointed to the struggle of frontline professionals to cope with strained resources, policy and managerial demands, professional cultures and personal costbenefits (Wells, 1997), our results add the crucial importance of communication and information to this array of needs. Our findings regarding the importance of crossorganizational and multi- and intersectoral information, communication and collaboration may indicate that work with the health refugee populations could currently be prone to fragmented organizational structures, a phenomenon that has been suggested to disrupt communication and information flow (Cebul et al., 2008). The cause of such fragmentation, obstacles to accessing and communicating information and the lack of institutionalized collaborative actions can be ascribed either to the novelty and extent of challenges associated with the establishment of newly resettled refugees or indicate a lack of adequate evidence on public health-level multi-sectorial actions (Tangcharoensathien et al., 2017) for promoting the health of refugee populations. Nonetheless, and given the importance of the discretion of street-level bureaucrats (Lipsky, 1980) in this regard, the results of the present study indicate that targeted efforts to facilitate these areas of communication are an important step towards promoting the health and establishment of newly resettled refugees in Sweden.

The results also concur with previous research undertaken in Sweden. For example, the environmental analysis carried out in southern Sweden (Kunskapscentrum migration och hälsa, 2017) points to the importance of collaboration with actors involved in 
migration and health. Initiatives in migration and health require actors to cross administrative and organizational boundaries and to make collaboration more effective and meaningful. An important strategy for working with diversity and health in Sweden, with a focus on the establishment of refugees, is thus to develop the possibilities for communications across and within the concerned institutions and organizations. The possibilities are many, and the interviewees in the study presented many suggestions about how to move forward.

\section{References}

Bhugra, D. (2004), "Migration and mental health", Acta Psychiatrica Scandinavica, Vol. 109 No. 4, pp. 243-258.

Blumer, H. (1969), Symbolic Interactionism; Perspective and Method, Prentice-Hall: Englewood Cliffs, NJ.

Bogic, M., Njoku, A., . and Priebe, S. (2015), "Long-term mental health of war-refugees: a systematic literature review", BMC International Health and Human Rights, Vol. 15 No. 1, available at: https://link. springer.com/article/10.1186/s12914-015-0064-9 (accessed 3 November 2020).

Brodkin, E.Z. (2008), "Accountability in street-level organizations", Intl Journal of Public Administration, Vol. 31 No. 3, pp. 1-35.

Cebul, R.D., Rebitzer, J.B., Taylor, L.J. and Votruba, M.E. (2008), "Organizational fragmentation and care quality in the US healthcare system", Journal of Economic Perspectives, Vol. 22 No. 4, pp. 93-113.

Cheng, I.-H., Wahidi, S., Vasi, S. and Samuel, S. (2015), "Importance of community engagement in primary health care: the case of Afghan refugees", Australian Journal of Primary Health, Vol. 21 No. 3, pp. 262-267.

Constitution of the World Health Organization (1946), "Constitution of the world health organization", American Journal of Public Health, Vol. 36 No. 11, pp. 1315-1323.

Conviser, R. (2007), "Catalyzing system changes to make HIV care more accessible", Journal of Health Care for the Poor and Underserved, Vol. 18 No. 3A, pp. 224-243.

Dahl, O. (2014), "Is culture something we have or something we do?", Journal of Intercultural Communication, Vol. 36.

Dahl, O., Jensen, I. and Nynäs, P. (2007), "Bridges of understanding", Perspectives on Intercultural Communication, Oslo Academic Press, Oslo.

Dahlgren, G. and Whitehead, M. (1991), Policies and Strategies to Promote Social Equity in Health, Institute for Futures Studies, Sweden.

Dooris, M., Farrier, A. and Froggett, L. (2018), "Wellbeing: the challenge of 'operationalising' an holistic concept within a reductionist public health programme", Perspectives in Public Health, Vol. 138 No. 2, pp. 93-99.

Evans, R. (2011), "Young caregiving and HIV in the UK: caring relationships and mobilities in African migrant families", Population, Space and Place, Vol. 17 No. 4, pp. 338-360.

Fazel, M., Wheeler, J. and Danesh, J. (2005), "Prevalence of serious mental disorders in 7000 refugees resettled in Western countries: a systematic review", The Lancet, Vol. 365 No. 9467, pp. 1309-1314.

Gerber, M., Callahan, J., Moyer, D., Connally, M., Holtz, P. and Janis, B. (2017), "Nepali Bhutanese refugees reap support through community gardening", International Perspectives in Psychology: Research, Practice, Consultation, Vol. 6 No. 1, pp. 17-31.

Hankivsky, O. (2012), "Women's health, men's health, and gender and health: implications of intersectionality”, Social Science \& Medicine, Vol. 74 No. 11, pp. 1712-1720.

Hill, C.J. and Lynn, L.E. (2016), Public Management: A Three-Dimensional Approach, 2nd ed., Sage, London.

Jensen, I. and Halkier, B. (2011), "Rethinking intercultural network communication as a resource in public intercultural health communication", Journal of Intercultural Communication, p. 25. 
Jervelund, S., Malik, S., Ahlmark, N., Villadsen, S., Nielsen, A. and Vitus, K. (2017), "Morbidity, selfperceived health and mortality among non-Western immigrants and their descendants in Denmark in a life phase perspective", Journal of Immigrant and Minority Health, Vol. 19 No. 2, pp. 448-476.

Kitzinger, J. (1994), "The methodology of focus groups: the importance of interaction between research participants", Sociology of Health and IIIness, Vol. 16 No. 1, pp. 103-121.

Krueger, R. and Casey, M.A. (2008), Focus Groups: A Practical Guide for Applied Research, Sage, Thousand Oaks, CA.

Kunskapscentrum migration och hälsa (2017), "Migration och hälsa; En omvärldsanalys utifrån kunskapscentrum migration och hälsas uppdrag”, available at: https://vardgivare.skane.se/siteassets/3.kompetens-och-utveckling/sakkunniggrupper/kc-migration-o-halsa/omvarldsanalys-migration-ochhalsa-i-region-skane.pdf (accessed 10 December 2018).

Kvale, S. (1997), Den Kvalitativa Forskningsintervjun, Studentlitteratur, Lund.

Lazar, J., Johnson-Agbakwu, E., Davis, O. and Shipp, M. (2013), "Providers' perceptions of challenges in obstetrical care for Somali women", Obstetrics and Gynecology International, Vol. 2013, doi: 10.1155/ 2013/149640.

Lindgren, T. and Lipson, J. (2004), "Finding a way: afghan women's experience in community participation", Journal of Transcultural Nursing, Vol. 15 No. 2, pp. 122-130.

Lipsky, M. (1980), Street-Level Bureaucracy, Russell Sage, New York, NY.

Lipsky, M. (2010), Street-Levle Bureaucracy. Dilemmas of the Individual in Public Services, Russell Sage Foundation, New York, NY.

Lövgren, V., Kalman, H. and Sauer, L. (2012), "Känsliga personuppgifter - mellan prövning och forskningspraktik", in Kalman, H. and Lövgren, V. (Eds), Etiska Dilemman, Forskningsdeltagande, Samtycke Och Utsatthet, Malmö, Gleerup.

Marmot, M. (2005), "Social determinants of health inequalities", The Lancet, Vol. 365 No. 9464, pp. 1099-1104.

Miller, K.E. and Rasmussen, A. (2017), "The mental health of civilians displaced by armed conflict: an ecological model of refugee distress", Epidemiology and Psychiatric Sciences, Vol. 26 No. 2, pp. $129-138$.

Morgan, D. and Krueger, R. (1993), "When to use focus groups and why", in Morgan, D. (Ed.), Successful Focus Groups: Advancing the State of the Art, Sage, Thousand Oaks, CA.

Navarro, V. (2009), "What we mean by social determinants of health", International Journal of Health Services, Vol. 39 No. 3, pp. 423-441.

Pejic, V., Alvarado, A., Hess, R. and Groark, S. (2017), "Community-based interventions with refugee families using a family systems approach", The Family Journal, Vol. 25 No. 1, pp. 101-108.

Riggs, E., Yelland, J., Szwarc, S., Casey, D., Chesters, P., Duell-Piening, S., Wahidi, F., Fouladi, F. and Brown, S. (2015), "Promoting the inclusion of Afghan women and men in research: reflections from research and community partners involved in implementing a 'proof of concept' project", Internation Journal of Equity in Health, doi: 10.1186/s12939-015-0145-3.

Sigvardsdotter, E., Vaez, M., Hedman, A.M. and Saboonchi, F. (2016), "Prevalence of torture and other war-related traumatic events in forced migrants: a systematic review", Journal on Rehabilitation of Torture Victims and Prevention of Torture, Vol. 26 No. 2, pp. 41-73.

Tangcharoensathien, V., Srisookwatana, O., Pinprateep, P., Posayanonda, T. and Patcharanarumol, W. (2017), "Multisectoral actions for health: challenges and opportunities in complex policy environments", International Journal of Health Policy and Management, Vol. 6 No. 7, p. 359.

Tinghög, P., Arvidsson, C., Sigvardsdotter, E., Malm, A. and Saboonchi, F. (2016), Nyanlända Och Asylsökande i Sverige: En Studie av Psykisk Ohälsa, Trauma Och Levnadsvillkor, Röda Korsets Högskola, Huddinge.

Vaughn, L. (2019), Psychology and Culture. Thinking, Feeling and Behaving in a Global Context, Routledge, London.

Vikdahl, L., Gunnarsson, D., Larsen, J., Ståhle, G., , and Saboonchi, F. (2018), Mångfald Och Hälsa: En Kartläggning av Vilka Kunskapsbehov Som Finns Hos Några Samhällsaktörer i Södertörnregionen Gällande Maingfald Och Hälsa, Med Fokus på Nyanländas Etablering, Flemingsbergs Science, Huddinge. 
Wells, J.S. (1997), "Priorities, street level bureaucracy and the community mental health team", Health \& Social Care in the Community, Vol. 5 No. 5, pp. 333-342.

WHO (2008), "Resolution WHA61.17 on the health of migrants", 24 May 2008.

Worabo, H. (2017), "A life course theory approach to understanding Eritrean refugees' perceptions of preventive health care in the United States", Issues in Mental Health Nursing, Vol. 38 No. 4, pp. 310-316.

\section{Further reading}

Aylesworth, L.S. and Ossorio, P.G. (1983), "Refugees: cultural displacement and its effects", Advances in Descriptive Psychology, Vol. 3, pp. 45-93.

Lag (2003), "om etikprövning av forskning som avser människor".

Vertovec, S. (2007), "Super-diversity and its implications", Ethnic and Racial Studies, Vol. 30 No. 6, pp. 1024-1054.

Yelland, J., Riggs, E., Wahidi, S., Fouladi, F., Casey, S., Szwarc, J., Duell-Piening, P., Chesters, D. and Brown, S. (2014), "How do Australian maternity and early childhood health services identify and respond to the settlement experience and social context of refugee background families?", BMC Pregnancy and Childbirth, Vol. 14 No. 1, doi: 10.1186/1471-2393-14-348.

\section{Corresponding author}

Linda Vikdahl can be contacted at: linda.vikdah|@gmail.com

For instructions on how to order reprints of this article, please visit our website: www.emeraldgrouppublishing.com/licensing/reprints.htm

Or contact us for further details: permissions@emeraldinsight.com 